PART II

Chapter 14

\title{
Basic Accounting and Compilation Guidance
}




\section{Introduction}

The System of Health Accounts provides a toolkit for describing and summarising health consumption expenditure that enables an analysis of the consumption, provision and financing dimensions of health care goods and services, both over time and between countries. This chapter describes some of the basic accounting guidelines for SHA and provides some initial assistance on compilation processes, including practical guidance on good accounting practice in relation to selected measurement issues.

The accounting principles are in addition to the SHA accounting concepts discussed in Chapter 3, such as coverage, timing of recording, cash versus accrual accounting, residents, valuation and the treatment of subsidies and non-market provision. The practical guidance on compilation processes presented here is not intended as a complete compilation guide, but merely outlines some of the main steps in creating health accounts, such as understanding the national health system, making an inventory of data sources, identifying data gaps, creating a health accounts database and ultimately filling the tables and presenting data.

Finally, the chapter provides practical assistance on some selected measurement issues across the function, providers and financing dimensions, introducing techniques such as prorating and discussing particular problematic areas such as the estimation of components of private health expenditure. More thorough guidelines are, or will become, increasingly available in some of these more complex areas of compilation as implementation experience improves.

The guidelines draw on and summarise material from the SHA guidelines, the Producers Guide and various OECD project reports, and, where necessary, update them in the context of SHA 2011.

\section{Basic accounting criteria}

SHA provides a framework that seeks to provide comprehensive coverage and consistent, internationally comparable estimated data that are as far as possible compatible with international economic statistical frameworks, in particular the SNA, and that are sufficiently accurate and timely to be useful for health policy analysis. Selected criteria on general data quality in relation to the main concepts of the SHA framework are addressed below.

\section{Comprehensiveness of coverage}

SHA seeks to account for the whole set of health system transactions, determined by the functional boundary set out in Chapters 4 and 5, that is, involving the health care consumption of the resident population irrespective of where the consumption takes place or who is paying for it. That means that it is not limited to government-financed or government-provided health programmes, but includes private transactions, either directly financed out of pocket by households or via third-party payers. In principle, it 
includes formal as well as informal transactions, provided that the health care criteria set out in Chapter 4 are met. The triangular nature at the core of the basic SHA accounting framework requires that the aggregate of these functional transactions is equal to the provision of these health care goods and services, and is equal in turn to the total financing by financing schemes. Beyond this set, totals may be different.

\section{Consistency and comparability of data}

SHA, by referring to common health care boundaries and classifications, enables the reporting of health expenditure estimates that are consistent over time. The internal consistency of the SHA's accounting rules and the consistency between components are important in cross-checking and validating estimates from different health dimensions.

The SHA's common boundary and categories for health systems may differ in some respects from those used in national health accounts for national purposes in a particular country. The purpose of a common boundary and sub-categories is to facilitate comparisons between countries as well as to track changes over time within countries.

\section{International compatibility}

The consumption-based accounting framework of SHA, with its set of expenditure tables, is designed to be methodologically compatible in basic terms with the System of National Accounts. This methodological compatibility with the SNA enables the calculation of a number of expenditure ratios that compare health expenditure aggregates with appropriate aggregates of the economy as a whole so as to facilitate international comparisons. For examples of such ratios, see Chapter 15.

\section{Timeliness and accuracy}

Health accountants must consider two other quality criteria when preparing the accounts. The criteria of timeliness and accuracy are both essential, but are also in conflict. It is necessary to establish a minimum level of detail and accuracy for regular reporting, while respecting a reasonable timeliness to address users' needs for data in order to inform, for example, any budgetary or policy adjustment process.

\section{Relevance}

The health expenditure data produced by SHA needs to be able to respond to the health policy questions and issues of the day, particularly at times of frequent changes in public policy in health care. In the past, for example, the monitoring of the economic consequences of health care reform was often obstructed by the inability of existing reporting systems to distinguish between changes in coverage and the mode of financing and actual change. The data framework should be flexible enough to adapt to current and future analytical requirements.

\section{Summary introduction to SHA compilation processes}

This section provides summary guidance on the main steps in building SHA accounts. It draws extensively on the EU SHA guidelines (and the Producers Guide), updating them for SHA 2011. This may be of assistance both for countries that do not yet have national health accounts (NHA) and more generally for those readers who are relatively new to health 
accounting. There is also a need for guidelines for the transition from SHA 1.0 to SHA 2011 for those countries that already have SHA-based NHAs. Such guidelines are expected to be developed separately.

Before any health accounting work begins, preliminary work will be necessary to gain a mandate, establish the project, involve the key institutions, fund and staff the project, and develop a plan with a timetable. From a value-for-money perspective, there are many advantages to planning for a regular production of health accounts, perhaps annually or every two years. This will in due course yield trend information as well as snapshots of the health system, and it will spread out the initial one-off start-up costs for the operation. In general, a stepwise approach is recommended for the whole process, with a few of the milestones described below:

\section{Step I. Understanding the national health care system under study}

Before considering data collection and calculation methods, it is worthwhile spending some time to understand how the national health care system works. This includes the preparation of a list of the financing schemes and the institutional actors (enterprises, government units, NPISH, households, rest of the world), along with their roles in allocating financial resources (collecting, pooling and purchasing) as well as of a list of providers of health care. The preparation of a chart on the financial flows can be useful, particularly if the units responsible for the flows are identified.

It might take some time initially to develop an overall view of the system, but achieving this will save lots of time and misunderstandings in the future. The national health system may be broken down into various sub-systems based on their relationship to public or private health care provision and financing arrangements, or into particular subsets of the population; this will help to identify the principal actors in the system. Examples may be found in the Producers Guide, Table 2.1 for Lebanon and, for a considerable number of countries, descriptive summaries of national health systems may be found at the website of the European Observatory on Health Systems and Policies, and more detailed information may be gathered from national sources.

A clear picture of the health care system should be drawn up that takes SHA definitions into account in order to avoid missing out on important parts of expenditure. As a starting point, it is worth looking for existing models put together by academics or other health care experts. Diagrammatic models of the national system may have to be remodeled according to SHA requirements based on consultation with a wide variety of colleagues, such as analysts from ministries, boards, trade associations and academic researchers, since the health care system is usually complex and in general no single person has a comprehensive understanding of all of its parts.

The initial model should show the flows of funds circulating within the health care sector and between the health care sector and the rest of the economy. This overview of the system is meant to outline all the major actors in the health care system and to link them according to the way funds flow between them. It should be noted that the same entity may appear more than once in the chart. Households, for example, can act both as providers of health care (household provision) and as the financing scheme (they buy health care goods and services out-of-pocket). Flows of funds should be identified at all levels, i.e. one should trace not only the payments made by financing schemes to health care providers but also the flow of funds to the financing schemes. In this initial view, the 
emphasis is on the identification of the flows and their direction rather than on the assignment of any monetary value to the flows.

\section{Step II. Setting the boundaries of NHA and clarifying any differences between the national boundaries of the health care system and SHA boundaries}

The SHA definition and boundary of health care is likely to be different to varying extents from the definitions and boundaries of health care used in national systems of health accounting due to differences in institutional arrangements, payment systems and country traditions. It is therefore important to identify the points of divergence between the two systems. For example, for those countries whose estimates of health spending are based on the national accounts, the main boundary difference will be that the national accounts place domestic production within the boundary, whilst SHA puts all domestic consumption within the boundary. Other key differences are the inclusion in SHA of items such as household provision of health care services and occupational health care. ${ }^{1}$ Experience from implementation in different countries has shown that the adoption of SHA definitions can make significant changes in estimates of current health expenditure as compared with national estimates, in some cases by as much as $1 \%$ of GDP or more (see Orosz and Morgan, 2004).

Even before embarking on SHA-based health accounts, many countries already have existing estimates of health care expenditure, and they use various national classifications to break down existing estimates. If there are national standards for classifying health care expenditure using the function, provider or financing dimension, then it would make sense to start from these and undertake a mapping exercise to construct correspondence tables to SHA classifications.

Identifying the existing national concepts and classifications is therefore one of the first steps in any health accounts compilation, and this can be very useful for spotting where there may be large differences between a national system and SHA. For example, health policy in some countries targets not only health care but also social care, and both types of expenditures may be included in existing estimates of health care expenditure. In other countries, expenditure related to long-term care activities may not be considered as health expenditure at all. If the difference between the national and SHA boundaries of the health system is not clearly understood, then there is a risk that some components of the health system as defined by SHA 2011 are not included in the national concept and therefore might be not taken into account.

Other examples are some of the activities related to environmental protection or hygiene that in some countries may come under the responsibility of the health care system and therefore be counted as health expenditure, whereas in SHA they are healthrelated functions and do not form part of total health expenditure.

In countries where the majority of health care expenditure is financed publicly, either through government finance (primarily from taxes) or social security funds, depending on the country, the first point of contact for establishing a working definition of what is considered to be health at the national level is likely to be the Ministry of Health or the Social Security Fund authorities.

\section{Step III. Investigating and evaluating data sources}

It is essential to identify and catalogue the available data sources along with their main characteristics, and make some assessment of their quality that can potentially 
provide information on the dimensions that they might serve. This stage should also see the construction of an exhaustive list of actors in the health care system identified in the previous step. These various health system actors and institutions may possess reports or records that could be useful. If some kind of national health accounts have been previously produced that may not have the same coverage and structure as SHA, the data sources used could still serve as a valuable starting point.

At this stage, the inventory of data sources is unlikely to be exhaustive. In the process of compiling health accounts, the investigation of potential data sources forms an important part of the development work. These may include the national accounts, any non-SHA health accounts, government records (for example, Ministry of Health budgetary information, regional government data) and Social Security data. These should then be complemented with other data and metadata obtained from, for example, insurance umbrella organisations, trade associations or NPISH financial accounts.

When making the inventory, each data source should be examined with the aim of finding out what the main content is, what information is provided, what questions are answered and what the original purpose of the source is. The aim here is to record all relevant metadata that will be of use when dealing with data for SHA compilation.

\section{Bottom-up or top-down?}

A top-down approach is used when most of the health accounts data are taken directly from pre-existing aggregate health expenditure classifications and recording systems. This often involves an extensive system of proxies and estimates to break down the aggregates. The technique of estimating through prorating is discussed in the section on measurement issues. An example of the use of aggregate estimates is where health accountants attempt to migrate directly from national accounts.

A bottom-up approach is used when most of the health accounts information is obtained using detailed information and data sources, for example, the internal reports of health insurance that describe both the scope and the values of services contracted with particular health care providers, and reports on the detailed activity of the Ministry of Health or NPISH that can be linked with financial information or budget data. Aggregate data may still be used and reconciled in the system.

This Manual recommends the advantages of a bottom-up approach under which various information sources, of both a monetary and non-monetary nature, can be used or combined either directly or using allocation keys for the purpose of data compilation. The advantage of a bottom-up approach is that it lowers the risk of double-counting of the same expenditure item, while enhancing provision of a mutually exclusive and exhaustive counting of expenditure. This is not to say that national accounts or other aggregate data are not useful, but the health accountant should as far as possible try to use detailed sources. This should be contrasted, however, with the top-down methods of allocation, once health expenditure aggregates have been estimated, for example, allocating hospital spending among the various functions (see Estimation through Prorating).

\section{Identifying the core data sets}

When compiling the inventory, each data source should be examined for: its original purpose, the main content, what information it provides, and what questions it answers. Some basic assessment of data quality would also be useful, including potential bias, 
accuracy and timeliness. All this will provide valuable metadata (information about the data) for SHA compilation and analysis. It is of vital importance to show the links of a particular database to the basic classifications of SHA 2011. The following items might be used to describe the data (IRDES and BASYS, 2007):

- Name of the data source;

- Administrator/Institution;

- Type of data source (registers, business surveys, etc.);

- Method of collection (e.g. administrative source, statistical full-scope or sample survey; national source versus standardised international survey);

- Availability of data (for which years data is available/data is used for SHA);

- Concept of the measuring units (costs, expenditures, turnover);

- Breaks in time (main methodological changes);

- Coverage of health actors (i.e. which categories of providers or financiers by HP and HF are covered; whether public or private institutions; national accounts sectors);

- Configuration of data (i.e. what dimensions of data are available: by HP, HC, HF, age, gender, diagnosis, geography, ownership, etc.).

Health accounts compilers need to deal with multiple data sources that primarily come from the financing or provider perspective, and they need to reconcile these sources continually. They also tend to use both basic data sources and aggregate information. Nonetheless, a generalisation can be made about the two approaches that health accounts developers tend to adopt when compiling health accounts.

- Financing approach: health accounts developers who follow this approach use data from the financing perspective as their main data source. The core data are financial data on expenditure by the different financing schemes. This information is then integrated with provider data sources where possible.

- Provider approach: health accounts developers who predominantly follow this approach use data from health care providers as their main data source. The core data are financial data on the receipts of the providers, but also data on the inputs used by the providers (mainly staff costs and intermediate consumption) and on their outputs (activities and their prices/costs). This information is then integrated with data from the financing side where possible.

Generally, when the information on the data sources has been collated, in particular on the availability, quality and timeliness of the data, a decision should be made as to whether the basic datasets will come primarily from the database of financing institutions or the database of providers. It may also be the case that different databases will be identified as core datasets for different functions (such as for pharmaceuticals and inpatient care). That said, all the relevant datasets needed to get a complete set of core accounts must be included.

If the databases of financing schemes (or agents) are the core data set, the first step is to make a qualitative analysis. This should include distinguishing the different types of government transactions: transfers from government revenues to financing schemes other than government schemes and the expenditure by government schemes. Another key issue is to clarify whether a financing agent (such as a social insurance agency or insurance company) operates more than one financing scheme. In such cases, expenditure by the 
different financing schemes should be treated separately. One special issue may be to estimate the administrative costs separately. It will be necessary to ensure that all spending on health care functions by financing schemes are included and that transactions for other purposes (e.g. government transfers to voluntary financing schemes) are excluded. The information from databases of financing institutions will then be integrated with information from provider and functional information, for example, but the benchmark figure for current health expenditure will be that based on the total health care expenditure of financing schemes.

If the databases of providers form the primary approach, the data from providers usually relates to their revenues. Exhaustiveness is again important, as the benchmark figure for current health spending will represent the total revenue of providers for the provision of health care goods and services to the resident population.

Ideally, health expenditure and its sub-aggregates are estimated according to both approaches, that is, using the databases of both the financing institutions and providers, and the relevant data are compared and the differences are analysed and reconciled.

Government agencies may play various roles in SHA - as a provider of revenues of financing schemes, a financing agent and a provider of health care - and some of those agencies not obviously involved in health may still hold useful information. Ministries of health, health system agencies, ministries of finance, national statistics agencies (likely to hold an array of relevant data sources), ministries of social services, social security agencies, central banks, regional or local government departments, financial regulators and business registries may all have relevant data sources. How much access national health accounts have to the data sources of these agencies may be another issue. These sources should be complemented by other sources, such as health insurance companies ${ }^{2}$ trade associations, commercial market information and NPISH accounts data.

\section{Step IV. Creating a health accounts database ${ }^{3}$}

After the inventory of data sources and an initial list of health system institutional actors and financing schemes, data should start to be compiled and recorded in a database or spreadsheets. The eventual structure of the database will be important, but at the outset a simple structure based on providers or functions, and which allows ample space for metadata descriptions, might be sufficient.

The following may be the main steps of the process:

- Deciding the structure of the database and the data-records;

- Deciding which data to acquire; entering existing data into the database;

- Allocating SHA classification codes to all data entries;

- Further investigation of gaps and data sources; and

- Finally, preparing the SHA tables.

An iterative approach is recommended so that initial estimates can be improved, data gaps addressed and data from different sources reconciled.

Which data are to be collected? In principle the more data the better, but there are cost considerations to bear in mind in acquiring data, both in terms of time and money. Some datasets may require a fee to be paid, which can be substantial. For other datasets, the burden on data providers in tailoring the dataset, or the time and other resources required of the team to acquire the data, should be considered. Of particular importance in the early 
stages of development will be to focus on the acquisition of data on expenditure. Other, non-expenditure datasets can be acquired at a later date when a view has been taken on the extent to which expenditure sources are sufficient. Some priorities may need to be established in the early stages, when expenditure data on the main health care functions may be most important. The data acquired are to be entered in the database and a provisional allocation by SHA classification made, a simple illustrative example is given in Tables 14.1, 14.2 and 14.3. The organisation of the database should be constructed while bearing in mind the nature of the health system and the availability of information.

Table 14.1. Provider example: hospital activity information

\begin{tabular}{lll}
\hline Hospital activity code & Description & HC Function \\
\hline HOSP1 & Accident and emergency department & Curative (HC.1) \\
HOSP2 & Orthopaedic Surgery & Curative (HC.1) \\
HOSP3 & Physical therapy services & Rehabilitative (HC.2) \\
HOSP4 & Mammography (breast cancer screening programme) & Prevention (HC.6) \\
$\ldots$ & $\ldots$ & $\ldots$ \\
\hline
\end{tabular}

Source: IHAT for SHA 2011.

Table 14.2. Source of funding example: Ministry of Health budgetary information

\begin{tabular}{lll}
\hline Code for budget item & Description & HC Function \\
\hline 1 & Diagnostic procedures not specified by function & Ancillary services (HC.4) \\
2 & Vaccination programmes & Prevention (HC.6) \\
3 & Purchase of MRI machines & Not HC but Capital Formation \\
4 & Civil servants pay & Health system administration (HC.7) \\
$\ldots$ & $\ldots$ & $\ldots$ \\
\hline
\end{tabular}

Source: IHAT for SHA 2011.

\section{Examples of initial allocation to SHA tables}

\section{A note on national and SHA health care boundaries and codes}

As indicated in Step II, it is necessary to identify significant divergences between national health accounts concepts and SHA 2011 concepts. Usually, all administrative data and data from business and household surveys are nationally coded as defined by national statistical classifications, which need to be mapped, as well as possible, to SHA 2011 codes. It is recommended to revisit these correspondence tables annually because of annual revisions of titles in the government health care budgets.

The SHA database should be integrated with the national health accounts database using dual coding that will allow simultaneous reporting according to national and international requirements. This also allows the presentation of health accounts for national purposes in a way that is different but consistent with international reporting.

\section{A more detailed allocation of SHA classification codes}

If dealing with detailed data records, in order to be able to achieve equality in total expenditure across the basic dimensions of functions, providers and financing schemes or agents, it would be useful to set up a database that allows for the simultaneous coding of data entries across several SHA classifications (see the example in Table 14.3). Further columns could be added as appropriate in the database, such as one for a sub-national regional identifier. 


\section{Resolving issues}

Following the initial allocation of data according to SHA classifications, a number of questions about the data source may arise. It is imperative to get into contact with the data providers and/or experts involved in the data source in order to discuss the use to which the health accounts compiler is putting the data. This will allow the expert to advise accordingly.

It is important to keep a record of issues related to the data, which may concern individual datasets or multiple data sets. What kind of issues may be encountered? These might include: no data available for some actors known to have expenditure on health care; insufficient health care functional information; a difficulty in splitting health care from, say, social care; a lack of information on cross-classification; contradictory results; and information on health care activities without the associated expenditure data.

These issues may lead to the need to acquire additional data, make assumptions on allocations, or use proxy variables and estimations for the reconciliation of contradictory results.

\section{Step V. Background calculations and filling the tables}

When the database is deemed to be as complete as possible and a final iteration and/ or checking have been done, the output of the process is the cross-classification of current health expenditure, initially by function, provider and financing scheme, and then any other tables that may be feasible. An important element of the work is to clarify whether background/working tables are to be prepared. For example, it may be useful first to prepare a separate HC x HF table for each financing scheme in order to reconcile subaggregates from databases of financing institutions and databases of providers separately for each financing scheme.

Finally, it is important to audit the compilation process for quality in terms of data, methods and data manipulation before the work is approved for publication. For this, descriptive information explaining the methods used in order to obtain the figures should also be presented. In particular, the relative quality of different parts of the table should be flagged and the reasons for this given. This also promotes the improvement of information, as data suppliers begin to understand how their information is used and to strive to make improvements in it.

\section{Step VI. Preparing a detailed documentation of the health accounts work}

It will be necessary in systematising the health accounts work for regular production to record the detailed data sources, calculation methods, adjustments and estimation procedures that are used in the production of SHA. This information may later be published in a more summary format to help users understand the results better.

\section{Step VII. Quality check of the results}

In addition to quality checks that should be built into the various steps of the production of health accounts, specific checks should also be performed on the final results. These checks will most likely include the confrontation of data from different sources, the validation of the latest year's data points with corresponding data points from the previous year and the investigation of any significant but unexplained changes. 
Table 14.3. Detailed representation of how data entries might be stored in a database

\begin{tabular}{|c|c|c|c|c|c|c|c|c|c|c|}
\hline \multirow{2}{*}{$\begin{array}{l}\text { Line } \\
\text { item }\end{array}$} & \multirow{2}{*}{ Year } & \multirow{2}{*}{ Description } & \multirow{2}{*}{$\begin{array}{l}\text { National area of } \\
\text { expenditure }\end{array}$} & \multirow{2}{*}{ Data source } & \multicolumn{4}{|c|}{ SHA 2011} & \multirow{2}{*}{$\begin{array}{l}\text { Amount } \\
\text { (Millions } \\
\text { NCU) }\end{array}$} & \multirow{2}{*}{ Comments } \\
\hline & & & & & $\mathrm{HC}$ & $\mathrm{HP}$ & $\mathrm{FA}$ & $\mathrm{HF}$ & & \\
\hline 1 & 2009 & $\begin{array}{l}\text { Radiation } \\
\text { oncology } \\
\text { services }\end{array}$ & $\begin{array}{l}\text { Public hospital } \\
\text { services }\end{array}$ & $\begin{array}{l}\text { Central } \\
\text { government } \\
\text { scheme (FA: } \\
\text { government } \\
\text { unit) }\end{array}$ & 1.1 .1 & 1.1 & 1.1 .1 & 1.1 .1 & 50 & $\begin{array}{l}\text { This } \\
\text { government } \\
\text { funding was } \\
\text { limited to } \\
\text { public } \\
\text { hospitals in } \\
2009\end{array}$ \\
\hline 2 & 2009 & $\begin{array}{l}\text { Ambulance } \\
\text { services }\end{array}$ & $\begin{array}{l}\text { Patient transport } \\
\text { services }\end{array}$ & $\begin{array}{l}\text { Private health } \\
\text { insurance } \\
\text { funds }\end{array}$ & 4.3 & 4.1 & 2 & 2.1 .1 & 40 & \\
\hline 3 & 2009 & $\begin{array}{l}\text { Breast cancer } \\
\text { screening }\end{array}$ & Preventive health & $\begin{array}{l}\text { Central } \\
\text { government } \\
\text { scheme (FA: } \\
\text { non-profit } \\
\text { institution) }\end{array}$ & 6.1 .3 & 6 & 1.1 .1 & 1.1 .1 & 100 & \\
\hline 4 & 2009 & $\begin{array}{l}\text { Dental services } \\
\text { paid by workers } \\
\text { compensation } \\
\text { insurers }\end{array}$ & Dental services & $\begin{array}{l}\text { Voluntary } \\
\text { insurance (FA: } \\
\text { injury } \\
\text { compensation } \\
\text { insurers) }\end{array}$ & 1.3 .2 & 3.2 & 2 & 2.3 & 5 & \\
\hline 5 & 2009 & $\begin{array}{l}\text { Departmental } \\
\text { costs of } \\
\text { Ministry of } \\
\text { Health }\end{array}$ & Administration & $\begin{array}{l}\text { Central } \\
\text { government } \\
\text { scheme (FA: } \\
\text { MoH) }\end{array}$ & 7.1 & 7.1 & 1.1 .1 & 1.1 .1 & 1000 & \\
\hline$\cdots$ & $\ldots$ & & & & & & & & & \\
\hline
\end{tabular}

Additional columns could be added for metadata, calculations, adjustments or estimation methods.

Source: IHAT for SHA 2011.

\section{Step VIII. Presentation of the results (output tables, key indicators, analysis for different audiences, etc.)}

The final step relates to the presentation of the results, giving key indicators and summary information about the data, such as any significant divergences from accepted standards or information on coverage. The presentation may also include some particular analyses for a particular target audience. Chapter 15 provides a further discussion of this step, with some examples of tables and indicators that health accountants can use or adapt, if they wish to do so.

\section{General measurement issues}

This section sets out some general measurement issues to bear in mind regarding the key concepts of the functional, provider and financing dimensions of the SHA accounting framework as well as certain specific parts of it, and it discusses the use of prorating as an estimation technique. It also considers the particular issue of estimating private health expenditure.

\section{Timing}

As stated in Chapter 3, this Manual recommends the accrual method, in which expenditures are attributed to the time period during which the activity took place, rather than the cash method, in which expenditures are registered when the transaction that 
paid for the activity took place. Recording on a cash basis can lead to a distorted picture; for example, budget or wage negotiations or health reform measures may entail spill-over effects from one fiscal year to another. Cash accounting is in many instances not compatible with the recording of non-monetary flows and with other economic statistics.

However, it is recognised that cash accounting may still be applied in some countries or in some parts of the health system. Health accountants may find a variety of accounting practices in their data sources, some accrual and some cash. Good practice should involve converting everything to an accrual basis to the extent possible.

For international purposes, this Manual recommends compiling health accounts on a calendar year basis. However, data are often reported according to different time frames; for example, government data may be on an alternative fiscal year basis. The easiest way to convert fiscal years to calendar years is to assume that expenditures occur equally in each month. It then follows that a portion of each fiscal year total can be allocated to a given calendar year. However, if price inflation or some other mechanism is believed to affect spending in each month, then a constant spending assumption is not a good one. In this case, a sort of indicator can be created that permits a change in the constant/ proportions adjustment. For example, in the case of price inflation, a monthly price index can be derived either from published sources or by decomposing annual inflation into monthly figures. The sum of those monthly figures can then be used to determine into what proportions to split the fiscal year total.

\section{HC The functional classification}

\section{HC. 1 and HC. 2 Curative and rehabilitative care}

In order to distinguish between the medical service functions (curative, rehabilitative and long-term care), it is the type of episode of care provided that is key. While the types of functions may have different cost profiles, particularly in hospitals, the difficulty many countries face in distinguishing between the first two medical services - curative and rehabilitative care - is acknowledged in the SHA tables, such that expenditure on these two functions may be combined into a single reporting item.

The broad definition of curative care in particular, with its consequent inclusion of a set of rather disparate activities, contrasts with the narrower definitions of other functions, which consequently tend to have more homogeneous sets of activities. In some countries, this contrast has led to this function being estimated by a residual: as total health expenditure (or medical services) less the other relevant functions.

Mode of provision and administration and hotel costs. At the two-digit level, cure and rehabilitation (as well as long-term care) are subdivided into the four types of mode of provision of care, i.e. inpatient, outpatient, day cases and home-based care. The subdivision of functions into these modes of provision is important for health policy purposes, and it is very useful to have data on totals by mode of provision in a country. Given the importance of this topic, a separate guideline has been written on modes of production in hospitals.

The concept of a mode of provision summarises a number of separate dimensions: i) whether or not the care is provided on the premises of the provider; ii) whether or not the patient is formally admitted for care on the premises of the provider (or formally discharged); and iii) whether or not the patient stays overnight on the premises of the provider. 
In order to avoid repetition, this guideline focuses on modes of provision in hospitals, but the principles are general and can be applied equally to other providers.

Where the care is provided at a patient's home, this is clearly home care. Where the care is provided on the premises of the provider, the modes of production are summarised in Table 14.4 .

Table 14.4. Allocation of institutional care to mode of provision

\begin{tabular}{lll}
\hline & Formal admission or discharge & No formal admission \\
\hline No overnight stay & Day care & Outpatient \\
Overnight stay & Inpatient & Not applicable \\
\hline
\end{tabular}

Source: IHAT for SHA 2011.

Inpatient care. For inpatient care, the "hotel costs" - cooking, cleaning, accommodation, but also the hosting of patients' relatives (if it is indispensable) - associated with the overnight stay of the patient should be included as part of the cost of health care where the main reason for institutionalisation is health care. This borderline poses a particular difficulty for mixed providers, that is, typically HP.2 Residential long-term care facilities. Inpatient care occurs mainly in hospitals, but also in other providers, for example, residential and ambulatory care, prisons and army hospitals. The term "inpatient" in SHA has a relatively wider meaning compared to some national reporting systems (where this term may be limited to inpatient care in hospitals).

Day care. Usually the stay (formal admission) lasts between 3 and 8 hours and often takes place in institutions or wards specialised for this kind of care, for example, elective surgery.

Outpatient care. Outpatient care is provided, for example, in a physician's office, hospital outpatient centres, ambulatory care centres and so on. It can also include tele-health services. Again, outpatient care in SHA may be defined more broadly than in some national reporting systems.

Home-based care. Home-based care excludes the consumption of medical goods dispensed in pharmacies as part of private household consumption. Examples of the type of services provided at home are obstetric services, dialysis, services provided by mobile nurses and health visitors, and long-term care (health and social).

\section{HC.4 Ancillary services}

HC.4: Ancillary services to health encompass a variety of services, mainly performed by paramedical or medical technical personnel with or without the direct supervision of a medical doctor. There are three sub-categories for ancillary services: HC.4.1: Laboratory services; HC.4.2: Imaging services; and HC 4.3: Patient transportation. The only ancillary services to be reported separately are those that are directly requested by patients and not intermediate services. Diagnostic services within outpatient departments are usually part of the bundle of activities of treatment and are therefore not to be excluded.

HC.4.3: Patient transportation comprises all such services - irrespective of the mode of production - even though these services are related to medical services that do have a mode of production dimension. 
These ancillary services are supporting activities rather than medical interventions, and do not necessarily require medical training or knowledge. In the inpatient and daycare modes of production, the costs of these services are difficult to separate out from the other costs of the medical services, and as such are not separately identified in SHA. In outpatient and home-care settings, SHA requires the ancillary services to be recorded separately. As delivery of health services differs across countries in terms of their mode of production, the relative proportion of ancillary services separately identified in SHA framework will also differ. Some countries have therefore found it useful for national purposes to collect information on ancillary services delivered in all settings. The "total" ancillary services figure, if compiled, could appear in national health accounts as a Reporting item.

Ancillary services may be provided in two main ways. Firstly, they may be provided by a different institution than are the medical services to which they relate. Secondly, they may be provided by the same institution. The availability of data and the corresponding methods for accounting for ancillary services provided may be different.

For ancillary services that are carried out in a separate institution, it is usually not difficult to find information about these activities and their costs. Regardless of whether one uses a demand or a supply approach, financial flows or output data of this type are clearly identifiable. If a hospital, for example, contracts out ancillary services to an independent laboratory, the financial flow will generally be easy to trace. The more difficult cases involve ancillary services that are provided in the same institution as the medical services.

There appear to be basically two current methods available to the compiler. In summary, the first method involves searching for information on financial flows. The second involves the commissioning of a specific study to examine expenditure on ancillary costs.

\section{HC.5 Medical goods}

The compilation of information on this item may be relatively straightforward, as medical goods are tangible and thus more easily accounted for. As several countries reported difficulty in distinguishing between goods associated with different modes of production, this aspect is abandoned in SHA 2011 and all medical goods sold directly to patients are included in this category of HC.5.

HC. 5 is divided into two groups: i) pharmaceuticals and other non-durable goods, and ii) therapeutic appliances and other medical goods (Table 14.5).

\section{Table 14.5. Consumption of medical goods non-specified by function}

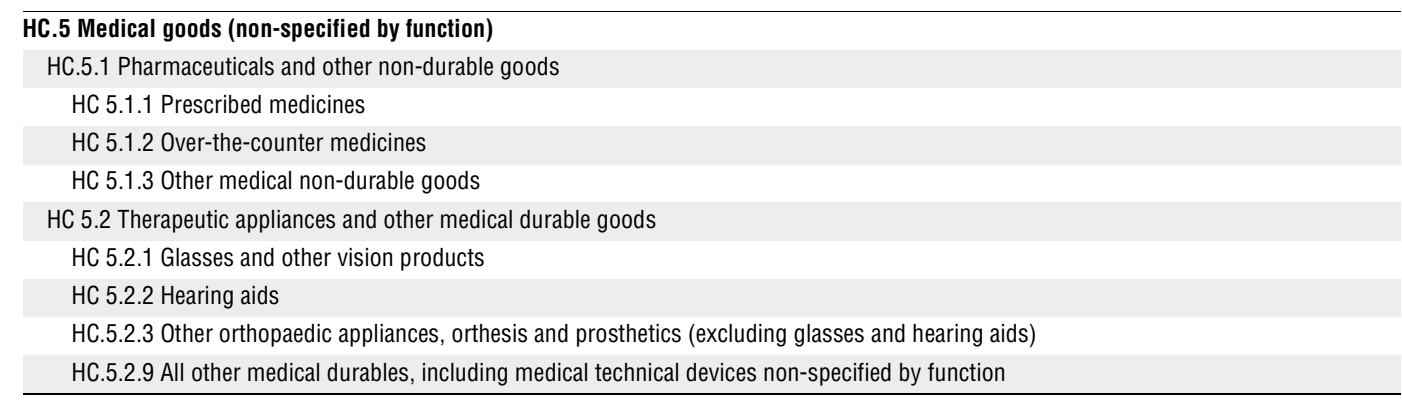

Source: IHAT for SHA 2011. 
It may be possible in some countries to find data from the provider side HP.5, such as retailers (pharmacies or supermarket sales of medical goods) and other providers of medical goods. It is also to be noted that there are strong links between HC. 5 and COICOP 6.1 (for more details see the annexes).

Information about private expenditures for medical goods can be found in business surveys. In surveys of pharmacies, total sales may be greater than sales of medicines, as they may also sell other products such as food, groceries and stationery. In these cases, adjustments may be required to exclude items that fall outside the scope of the health accounts concept of final expenditures for health, and additional supplementary data may be needed to adjust the primary data (see Rannan-Eliya and Lorenzoni, 2010).

Additional areas to be tackled cover such issues as how to apportion the different health care functions, e.g. administration in health insurance or integrated curativerehabilitative-preventive services, and how to separate health care functions from other activities, such as research. Some guidance in these areas can be gained from the section on prorating.

\section{HP The provider classification}

The provider approach is used by compilers who use "provider-based data" as their core dataset. Expenditure on health care when derived from this approach will mainly be based on information obtained from the financial receipts of providers. Examples of the key data sources used when following this approach are: business surveys, surveys on financial activities, accounting information submitted to statistical offices and tax offices, and market information, such as information on supply and demand collected by market research companies. When this type of information is unavailable or incomplete, an estimation of receipts may be obtained by using information on inputs and their costs (staff wages and intermediate consumption) as well as output or activity information (number of activities performed and their respective prices or costs). However, attention should be paid to the possibility of double-counting. As described in Chapter 6, when a hospital contracts laboratory services from an independent ancillary service provider, the health accounts compiler must ensure that this expenditure is not counted twice; once when analysing hospital accounts, and a second time when looking at the ancillary service providers' accounts. In addition, when using this approach care must be taken to exclude non-health expenditure borne by the provider (e.g. expenditure on social care).

In terms of the general process: first, the health accounts compiler organises the database comprising the universe of health care providers to include both primary and secondary providers for all activities that are identified as health care within the functional classification. To estimate the value of health care goods and services provided, it can be particularly important to separate providers into market and non-market providers. The second step comprises an estimation of the health care-specific provision value, to equal the revenues from financing schemes. The HPxHF cross-classification table helps to estimate and reconcile the money flows of current health spending from the financing schemes to providers as well as supporting further reconciliation with a functional breakdown.

\section{HF, FS and FA The financing classifications}

The original sources of detailed data on financing will come from some of the institutional units involved in the health financing system. These may include government 
ministries, government agencies, health insurance agencies, NGOs, health providers, households, enterprises and foreign donors.

As funds may pass through one or more intermediate agencies, it is important to ensure that there is no double-counting and that all the funds made available for the provision of health care goods and services are identified.

This Manual identifies financing schemes as of interest for international comparison and policy monitoring over time. However, the core information on schemes and their revenues are typically derived from the data coming from the financing agents who manage the schemes or from the institutional units that provide revenues to financing schemes, as each financing agent or institutional unit that funds schemes may either manage or participate in one or more schemes. For further information, see Chapters 7 and 8. Guidelines separate from this Manual will provide detailed assistance to compilers for the implementation of classifications of health financing under SHA 2011.

Box 14.1 provides a far from exhaustive list of compilation issues that concern some of the other chapters of the Manual, and which could be considered in the development of additional guidelines and good practice.

\section{Estimation using prorating}

This section aims to guide the data generation of expenditure under a top-down approach, which involves distributing an aggregate among components. In many endeavours the data can be too aggregated to be broken down into specific services. This methodological approach has been validated in the field as feasible and convenient for general health accounts, but guidance on how to distribute the expenditure is required. The usual approaches followed are:

a) Allocation using the main activity principle of an industry classification. This approach can lead to major distortions of spending and is thus not recommended except when it refers to minor components of health spending. One difference with the SNA is that for the total economy, eventual distortions are not as relevant because the important point is to have all resources integrated. However, for a functional exercise, where the aim is to have an idea of levels by class, distortions can potentially damage the data credibility. Nonetheless, this approach could be useful as the starting point for both the provider divisions and the linkages to ISIC/NACE on production.

b) The development of specific studies. These can vary largely in scope as well as in the accuracy of their results. It can include anything from focal groups or expert opinions, to measuring actual activities through "time and motion" studies. These studies involve resources and time that can be adapted based on country conditions. The recommendation is to analyse previous experiences and to the extent possible, to draw on closely related examples. If more accurate estimation methods are needed, then a more bottom-up approach is suggested.

c) Allocation using keys. The allocation of aggregates usually involves the use of reference values or allocation keys. The process is to identify an available value that can reliably reflect the amount of resources and expenditure involved in the various components included in the aggregate to be divided. The basic information can refer to service unit costs or the human resources involved and/or the quantity of specific services provided. Composite indexes that account for various inputs and costs have also been generated, according to the available information in the field. 
d) Case-by-case adjustment. Some adjustments can be decided on a case-by-case basis. For example, the expenditure on the administration of insurance companies could be distributed in proportion to total expenditure in the class.

\section{Box 14.1. Other selected compilation issues}

Factors of provision

How to identify and estimate expenditure on intermediate consumption

How to estimate income of non-salaried self-employed professionals

How to estimate capital consumption

Beneficiaries

How to identify appropriate distribution keys

How to split expenditure by disease group

How to estimate income/expenditure groups

Capital formation

How to estimate investment on R\&D and E\&T

How to estimate values on household improvements with a health purpose

How to handle foreign investment

External trade

How to deal with illegal or unethical trade (e.g. of organs)

How to handle major differences between the resident and covered population

How to handle major differences on valuation in origin and destination pricing

How to determine when medical tourism is important and needs more consideration

This type of prorating is commonly used to fill the gaps when expenditure tracking records are insufficient to estimate the specific outlays. The general overview can be applied to further split the expenditure on health on the selected services in a top-down approach: inpatient care, nursing homes, outpatient care, pharmaceutical provision and prevention.

A brief description of this approach is included in the Guide to Producing National Health Accounts (PG) and can be applied to the distribution of expenditure by beneficiary for age, gender and disease in paragraphs 14.74-14.93 (WHO, World Bank and USAID, 2003).

\section{The underlying principle for prorating}

The underlying principle is the equation:

Value $=$ price ${ }^{*}$ quantity

Boundary setting. A definition of the components to be estimated has to be clearly established to set the boundary of the estimation.

Partition of current expenditure into homogeneous cost blocks. The data to be distributed are taken from the health accounts aggregates: those handled frequently appear to be, in particular, inpatient care/outpatient care in hospitals; nursing homes: for health care and social care; outpatient care: for curative and rehabilitative care; and some components of prevention. Whenever possible, each component should be disaggregated into smaller units to ensure a better cost linkage. 
Distribution of current expenditure through utilisation keys. Distribution keys are estimates of the distribution of health care use over distinct combinations of all dimensions, and they are linked to each cost block or cost group. Every key receives a fraction of total utilisation within the group. Some requirements of the use of keys have to be fulfilled: all together they have to add up to $100 \%$ of the care delivered, with no double-counting of the services, as the distribution refers to indicators of the health care utilisation and the cost unit. Thus, the nature of such indicators should reflect a relationship to the resource cost of the associated health care services: unit costs, human resources or services consumed.

The utilisation keys (percentage shares) by cost group are multiplied by the total spending or an aggregate to be allocated, and are then added up. The results should be analysed and validated through per capita values, obtained by dividing the expenditure by subclass by the population.

\section{Some examples of utilisation keys}

For inpatient care: hospital days, admissions, patients, procedures. This is preferably adjusted by type of hospital.

For providers of ambulatory health care: contacts, visits, treatment sessions.

For preventive services: covered population.

This type of approach, although imperfect, can be performed with limited cost and has been progressively refined, e.g. to distribute expenditure using available data, such as for costs. The closer the costing studies relate to the type of service consumed, the more appropriate the information for expenditure purposes, e.g. costing studies should reflect medical units stratified according to the level of care and the technological complexity and/or size of the unit. Cost analysis may be linked to services and to cost centres. The distribution of cost centre costs can also be made using human resources, e.g. ward costs, bed-days, IP drugs - actual drug costs/numbers, theatre costs, radiology. In fact, an indirect use of the cost is made to estimate intermediate values, then the distribution profile is identified and then applied to "weight the component".

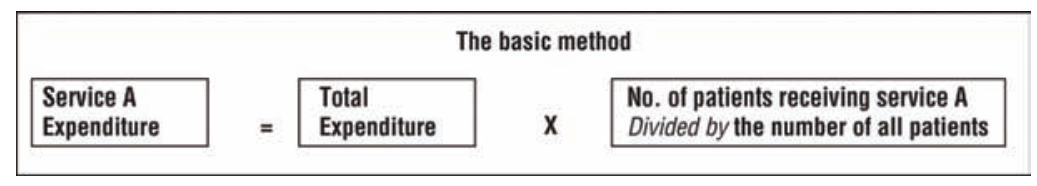

As data that can directly provide the expenditure by service are generally not available, there is a need to identify a way to allocate the expenditure, which, again, is linked to other data availability. A mix of data and of keys may finally be used. There is a need for periodic quality verifications to ensure that the best approach has been taken.

Each set of expenditures may pose additional problems to be solved, for example, in practice, units may be either non-market providers or market providers, requiring different measurement methods in the two cases. ${ }^{4}$ 


\section{1) Non-market provider units}

The basis of measurement is cost (not price). The data available include budgetary spending and user charges, which should be distributed according to the cost of production. In countries where hospital budgets do not differentiate inpatient from outpatient inputs, an estimate of inpatient share could be needed.

\section{2) Market provider units}

The basis of measurement is price (not cost). In most countries, obtaining the data may be difficult. Possible alternatives are household surveys data or insurance claims data. Caution is advised when the insured population is not representative.

\section{Measurement issues in a special case}

\section{Private health expenditure}

Incomplete sources and estimation methods for components of private expenditure on health are widely thought to be a major limitation for international comparisons.

The principal source of problems in the measurement of private health expenditures is the inherent tendency both for much private health care financing to occur without the generation of linked, reliable and comprehensive routine data, and for private providers, who are more likely to be financed by private expenditures, to tend to operate without reporting routine data to statistical agencies. The frequent lack of suitable registration data for private providers reinforces the difficulties, since this limits the potential for comprehensive and representative surveys. As a result, in the absence of routine, administrative or transactional data, an estimation of private health expenditures must often rely on the use of survey data. The production of reliable estimates thus requires considerable care in the selection of appropriate methods, in the assessment of the available data, and in combining information from multiple data sources.

The data sources currently used to estimate private expenditure components such as household budget surveys and data reported in national accounts have been developed for other purposes. A mapping of national categories to the International Classification of Health Accounts (ICHA) is therefore often difficult due to differences in concepts and definitions and in the exhaustiveness of classifications.

The OECD guidelines (2010) on measuring private health expenditure present a set of recommended approaches to measuring private health expenditure. These are based on a review of known problems in private expenditure estimation and on consideration of the reliability, reproducibility and feasibility of current and potential methods. As such, they provide a platform for ongoing work to develop improved methods.

Private health expenditures are expenditures whose final purpose is health care and which are financed by all resident institutional units other than those belonging to the government or compulsory insurance schemes. Expenditures that mainly cover voluntary health insurance and out-of-pocket expenditures are categorised as HF.2 and HF.3 by the ICHA-HF classification.

The guidelines provide advice on the general approach to be taken in measuring private health expenditures, in particular how a measurement strategy should be formulated, and how data sources and methods should be identified. They also provide a tool for a national self-assessment of existing methodology. They review in detail potential 
methods for estimating private expenditure flows, with those specific to financing agents presented before those specific to providers. The specific methods for estimating household out-of-pocket expenditures are only presented afterwards, as these require consideration of when and how household survey data can be used. Finally, the guidelines discuss how the different estimation methods and data sources can be combined to produce overall and final estimates in an integrative approach.

The measurement strategy:

- Foresees the decomposition of the HF.2 and HF.3 measurement problem into separate and independent estimation problems:

- Segregation of financing flows in practice;

- Variation in data sources by financing flow;

- Independence of errors in individual components.

- Considers each financing flow as three elements:

- Level;

- Trend;

- Composition.

- Suggests that the optimal strategy may be to estimate an aggregate first, and then to estimate distribution by providers/functions

This measurement strategy also suggests using an integrative approach, which foresees the use of information from different perspectives on each set of transactions to triangulate best estimates of actual financing flows from three perspectives: financing; provider; and consumption (in terms of composition of expenditures).

Usually, a variety of methods are potentially available for estimating any specific expenditure flow. Some are more reliable than others. To indicate this, the guidelines classify methods into three groups based on quality and reliability:

- Methods that are reliable and ideal, which are most appropriate;

- Methods that are less reliable, but are acceptable if ideal methods cannot be used; and

- Methods that are not acceptable except as a last resort.

Health accountants are encouraged to evaluate the quality of the data sources for private health expenditure and use integrative triangulation methods to confront the data sources.

Further information can be found in the OECD guidelines on measuring private health expenditure.

\section{Notes}

1. See Annex B for a full description of the links and differences between SHA and National Accounts.

2. In addition, other insurers, for example, injury compensation insurers, may have some relevant information.

3. Steps IV together with various other steps are to be considered an iterative process. There will be an initial compilation of the database using identified data sources. It is then important to consider whether there are any gaps or problem areas in the database, which should lead to a search for additional data sources. These should be confronted with the database and estimations made as necessary. This iterative procedure is repeated until the database achieves a sufficient stability and quality.

4. For more discussion of measuring non-market provision, see Chapters 3, 9 and 13. 


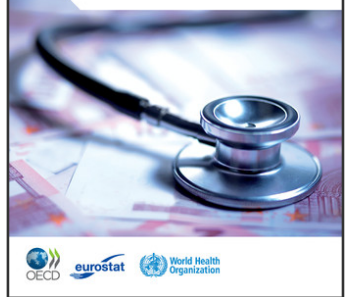

\section{From:}

A System of Health Accounts

2011 Edition

Access the complete publication at:

https://doi.org/10.1787/9789264116016-en

\section{Please cite this chapter as:}

OECD/World Health Organization/Eurostat (2011), "Basic Accounting and Compilation Guidance", in A System of Health Accounts: 2011 Edition, OECD Publishing, Paris.

DOI: https://doi.org/10.1787/9789264116016-16-en

This work is published under the responsibility of the Secretary-General of the OECD. The opinions expressed and arguments employed herein do not necessarily reflect the official views of OECD member countries.

This document and any map included herein are without prejudice to the status of or sovereignty over any territory, to the delimitation of international frontiers and boundaries and to the name of any territory, city or area.

You can copy, download or print OECD content for your own use, and you can include excerpts from OECD publications, databases and multimedia products in your own documents, presentations, blogs, websites and teaching materials, provided that suitable acknowledgment of OECD as source and copyright owner is given. All requests for public or commercial use and translation rights should be submitted to rights@oecd.org. Requests for permission to photocopy portions of this material for public or commercial use shall be addressed directly to the Copyright Clearance Center (CCC) at info@copyright.com or the Centre français d'exploitation du droit de copie (CFC) at contact@cfcopies.com. 